\title{
The Investigation and Optimization Strategy of Rural Art Education
}

\author{
Xiaobing Hu \\ Fine Art Academy, Anqing Normal University, Anqing, China \\ Email address: \\ 315698886@qq.com \\ To cite this article: \\ Xiaobing Hu. The Investigation and Optimization Strategy of Rural Art Education. Arabic Language, Literature \& Culture. \\ Vol. 4, No. 2, 2019, pp. 41-47. doi: 10.11648/j.allc.20190402.12
}

Received: September 10, 2019; Accepted: September 26, 2019; Published: October 10, 2019

\begin{abstract}
Art education in primary and secondary schools is indispensable to the implementation of quality education in basic education. The aim is to make students feel excellent art works and culture, expand their aesthetic education knowledge and open their students' vision and improve their aesthetic appreciation. However, through the investigation, the current situation of the art teaching in the primary and secondary schools is not the new teaching thinking, the teaching tool is old and so on. Under the great background of the present core literacy, fine arts education is of great significance to the improvement of the students' humanistic quality. How to make the students have a great interest in the art appreciation, and enjoy the fine art works in the teaching of music, from which the relevant knowledge such as the humanities, the art and the culture can be obtained? The method is as follows: flexible and variable and shape With the rich teaching method, the art teaching of primary and middle schools is carried out, the art teaching is expanded by the path of the field teaching, the artistic charm of the body is improved in the appreciation of the outstanding works, the cultural self-confidence of the students is enhanced by the comparison of the Chinese and western cultures, To make the art teaching of primary and middle school realize the goal of core accomplishment in a rich and colorful life. Conclusion: the child is like a u-disc whose content is dependent on the stored content. In the course of the elementary and middle school fine art teaching, the organization form of the course is remarkable to the effect of the teaching effect, the core quality is the main index element, the fine art class is active, and the student's fine art operation ability can also be obviously improved.
\end{abstract}

Keywords: Rural Art Education, Present Situation, Recognition Strategy, Optimization Strategy

\section{Instruction}

In "Yin Shaochun on Art Education", Professor Yin Shaochun puts forward that the core literacy of art subject includes image recognition, fine art express, aesthetic judgment, creative practice and cultural understanding. (Figure 1) Art teaching is an important part of school education. Art teaching can not only cultivate students' visual cognition, but also improve students' aesthetic ability and cultivate noble sentiment. At the same time, art appreciation plays a significant role in improving students' cultural and humanistic literacy, opening up students' horizons, increasing knowledge and so on. However, in the basic education survey in rural areas, many problems have been found in rural art education. Such as the rigid teaching model, the lack of attention to the author's thoughts and feelings in the creation and the background of the times, the existence of many concept teaching methods, neglecting the interactive nature of teaching, how to change the problems faced by rural art education, this is exactly what this article is about.

\section{Investigation of the Status of Rural Art Education}

The basic education in rural primary and secondary schools is now a key point in education reform. Due to the long-term lack of attention to education, basic education in rural areas has always had some complicated issues, such as: shortage of teachers, outdated infrastructure, The ideological knowledge of the educator is not high, the educator's thinking is low, and so on. However, art education is a weak link in basic education, mainly reflected in: 1. the lag in ideological understanding is the fundamental problem that causes the status of rural art 
education. For a long time, fine arts, music, and sports have not received much attention in rural basic education. Some rural primary and secondary schools do not have art courses at all. Even if some schools arrange art classes, they lack the corresponding professional teachers and basic teaching facilities. For a long time, the fine arts teaching in students' thinking is the same as that of physical education class. This situation has caused the art class to be inexplicable; 2 . The shortage of teacher resources is the most serious problem in rural art education. The art education in rural areas still stays in the understanding of the deputy section. Bring a teacher with him or a teacher with a slightly older age to attend art classes, further exacerbating the problem of art education in rural areas. As we all know, fine arts is a highly professional discipline. Without a certain degree of professional training, it is impossible to teach fine arts. In addition, some teachers only teach students how to draw a flower, a horse, a sheep and the like during the teaching process. These paintings have no new meaning at all. They are still children's simple paintings in the 1960s and 1970s. Adapt to the current needs of children and adolescents. What they need is truly artistic things to satisfy their desire for artistic pursuits. 3. The backwardness of infrastructure is also an issue that cannot be ignored in rural art education. The art education in rural areas in some places, there is no basic infrastructure at all, which brings a lot of inconvenience to rural art education.

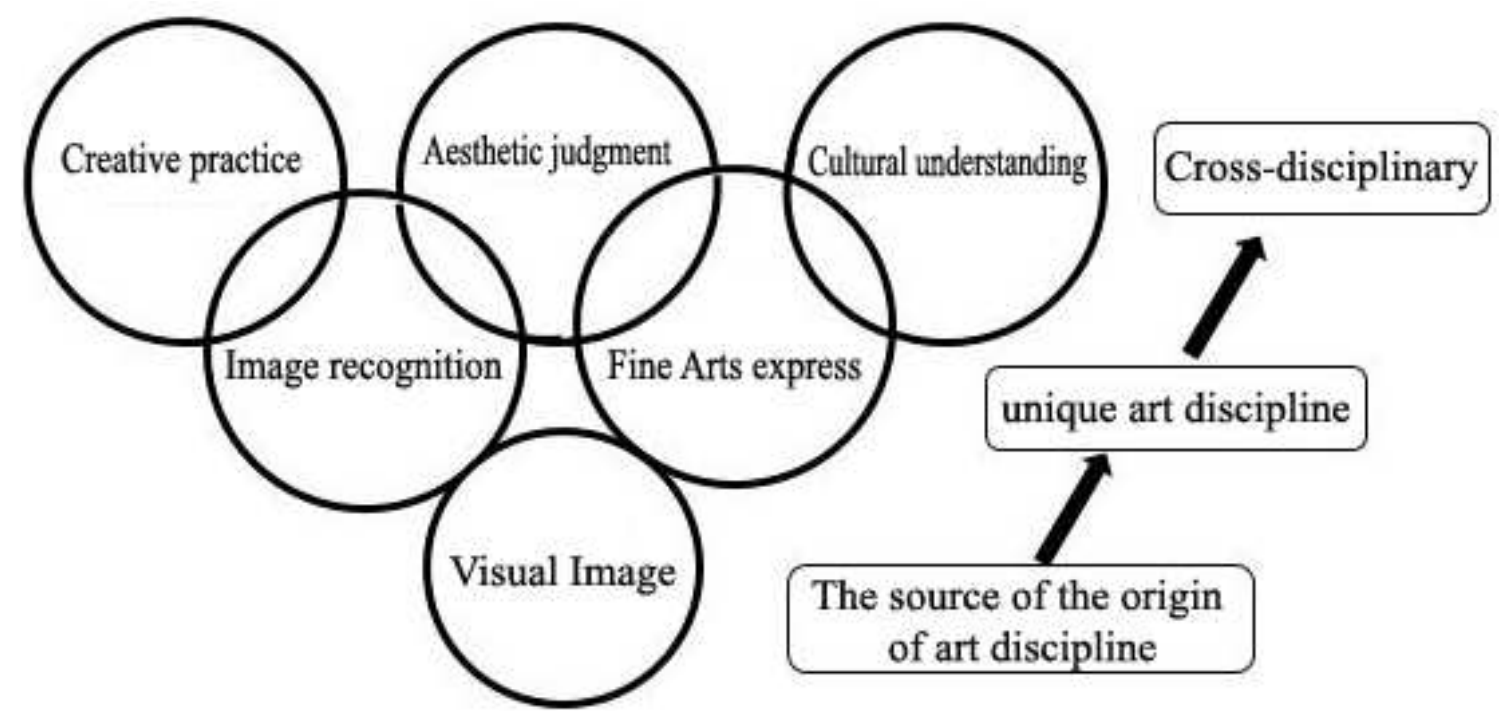

Figure 1. Core Literacy structure view.

The art education in primary and secondary schools is the stage of initiation of learning. Children at this time, due to the constraints of both age and psychological factors, often encounter difficulties and frustrations in the learning process, they will have a fear of emotion, the persistence of attention is low, and there is a lack of understanding of the creation of the art class. These make the art discipline, which should have been full of vitality, overshadowed by children [1]. Then, how to guide children to overcome the impetuousness of this knowledge-seeking process and let them fall in love with this class, so that we have to re-examine our education. We should use Marxist dialectical method to look at education, clarify the dialectical relationship between internal and external factors, and make clear that the internal cause of education is students. Only if internal factors are fully mobilized, education can cultivate the next generation with innovative consciousness, innovative spirit, and innovative ability.

\section{Problems Raised: The Implementation of Classroom Teaching Objectives}

Personalized education is an important feature of future education. Under the premise of acknowledging the commonness of students, it emphasizes the cultivation and exertion of students' individuality in the teaching process, and highlights individual differences among students. In the process of personalized education, emotional communication and communication between teachers and students are strengthened, students can exert greater enthusiasm and subjective action, thereby enhancing self-learning, observation, analysis, judgment ability and self-identification, self-evaluation and self-control ability.

Due to the long-term influence of exam-oriented education, some teachers did not really achieve the "development based on students" required by the concept of quality education. For example, they let students discuss in class and hands-on exercises. On the surface, students seem to be very being active and thinking started, but the teacher finally used a standard answer to virtually limit the student's thinking. The student still had to follow the teacher's thinking. Through a large number of practical exercises, although the students' painting skills may be improved to some extent, this is not conducive to the formation of students' sense of innovation and personality development. In my opinion, the "advanced student-oriented" advanced teaching philosophy advocates that teachers not only teach students to master basic painting skills, but also teach students how to paint what they want to draw in their hearts, and even paint better. The traditional art 
teaching model takes the categories and paintings as the teaching context. It focuses on the teacher as the center and teaches the students how to paint. The modern art teaching model advocates students as the center and the teacher helps the students to draw the things they want to show. Better is how the teacher helps the students to draw. For example, the second "Comic" teaching, using multimedia teaching methods to show celebrity comics, so that students of various forms of comics at a glance; the use of PHOTOSHOP's technology to modify the picture, so that the character's characteristics are more exaggerated, so as to achieve the comic effect. Encourage students to use the special features of comics to vividly depict things in life, so that students can distinguish between truth, goodness and beauty.

Optimizing art classroom teaching is an art, not just a technology. It plays a significant role in developing students' learning potential and cultivating their innovative awareness and ability to innovate. Art teachers must keep pace with the times and have people-oriented thinking, grasp the physical and mental characteristics and cognitive rules of students of different ages, study education teaching methods and improve teaching, so as to improve the art of art classroom teaching.

Rural art education activities provide students with a wide range of opportunities to participate in social activities and creative activities. This space is also a very intuitive and effective art thinking activity, and plays a pivotal role in transforming students from individual to social. In short, rural arts education activities are not a single way of learning. At the same time as they acquire skills and skills, they must also value the overall development of students in other areas. Through the teaching of fine arts, students can be socialized. However, the benefits of learning fine arts are more than just the students. As long as teachers are able to be student-oriented, guide students to discover beauty, express beauty, and create beauty, and use art activities to promote students' whole body and mind's healthy development and the improvement of their overall quality, then the true value of rural art education can be realized.

\section{The Optimization Strategy of Rural Art Education}

In view of the current state of rural art education, I believe that rural education must deepen reform. In June 2000, according to the spirit of the "Outline for Basic Education Curriculum Reform (Trial)" of the Ministry of Education, the Research Group for Art Course Standards set out to study and formulate curriculum standards. After many revisions, in March 2001, the "Full-time Compulsory Education Fine Arts Curriculum Standard (Consultation Draft)" was completed. After many opinions were solicited, the amendments were finalized. In July of the same year, the Ministry of Education announced the "Full-time Compulsory Education Art Curriculum Standard (Experimental Draft)" [2]. The core link of the art curriculum reform is the implementation of the art curriculum, and the basic approach to curriculum implementation is to optimize the teaching model. Classroom is the location of the teacher's teaching stage and is the birthplace of student wisdom. In order to make students move, let the classroom live, let love fill the entire classroom, let the students taste the natural science in the simple classroom life, we need to use the love between teachers and students to arouse the children's curiosity, use skills to guide students Comprehensive and harmonious development will create a democratic and harmonious development space for students.

\subsection{Develop Rural Resources and Guide Students to Experience Natural Sciences}

Classroom teaching should closely link the classroom with life. This is one of the basic concepts of the new curriculum. The curriculum resources can be divided into two major categories of material resources and conditional resources according to functional characteristics. According to the spatial distribution, curriculum resources can be divided into campus curriculum resources and off-campus curriculum resources [3]. On-campus fine arts curriculum resources can be further divided into: first, library data resources. Second, the place where art works are displayed. The art curriculum resources outside the school are rich and varied, mainly including: first, public cultural facilities; second, local cultural resources and natural resources; and third, artist studios and art workshops. In addition, we also need to expand the curriculum resources: 1. important local material. Learning objectives include: how to deal with local religious beliefs, history and geography, arts and crafts, genres of dance and drama, local languages and cultures, biographies of well-known local people, local laws and customs, and so on. 2 . Add some new content for the basic course. It enriches science, history, and literature into obsolete textbooks. 3. Combine basic courses with other subject areas to form a new course. 4, increase some basic courses do not have content. Usually, these contents are topics that teachers are good at or have special interests [4]. We can put students' works on the wall and let everyone comment together; we can make paintings to allow students to observe things, experience life, and stimulate imagination; we can also use natural resources and use mud. Students are allowed to make clay sculptures; we can also collect a variety of waste materials to make sculptures, stand in rice fields, guard rice fields, and prevent birds from eating immature rice. Let life be classroomized, let the classroom live, guide students to apply natural science knowledge to students' experience in life, and make students fully understand that natural science comes from life and it is the basic tool to solve life problems and achieve natural science classroom The purpose of teaching life. The study of natural science is based on daily life. Learning natural science is to better solve the problems in life and better experience life.

\subsection{Create a Situation to Stimulate Student Interest}

The important reform in the new curriculum standards is to focus on the cultivation of students' emotions and thinking. Effective classroom teaching can inspire interest in learning 
and create a good learning atmosphere. Students can take the initiative and devote themselves wholeheartedly to learning. The teaching content should make full use of students' life experiences and real-life examples. According to the teaching content of this lesson, teachers and students jointly create a vivid, interesting and vivid learning situation that can guide students to participate actively. The situation created must have the function of attracting students' attention and improving students' interest in learning. What's more important is that the situation should be full of meaningful and challenging natural science problems. Situations are created in the form of storytelling, games, visual presentations, dialogue performances, operational experiments, multimedia projections, etc. Students are then allowed to observe, manipulate, guess, communicate, question, discover, and raise natural science problems.

\subsection{Take the Initiative and Encourage Independent and Cooperative Learning}

In order to maximize the degree of students' active participation in learning, the independent, exploring and cooperative learning methods are used. Students are not a blank sheet. Even first-year students have some natural science activity experience and knowledge accumulation. Therefore, in teaching, students are not allowed to passively absorb, imitate, memorize, and practice repeatedly. Instead, they create learning situations that involve hands-on practice, independent exploration, and cooperative communication. A large number of observations and studies have fully proved that students' learning can be really effective only when they feel that others care about them; they are very curious about what they are learning; actively participate in the learning process; Get the right feedback after the task is done; see opportunities for success; be interested in what you are learning and feel challenging; feel that they are doing something meaningful. To promote student self-development, it is necessary to create teaching conditions as much as possible so that students can participate in the context and atmosphere of autonomous learning.

Cooperative learning refers to mutual aid learning where students have a clear division of responsibilities in order to accomplish common tasks in groups or teams. It includes several factors: 1 . Actively assume personal responsibility in accomplishing common tasks; 2 . Active mutual support and cooperation, especially face-to-face promotional interaction; 3 Expect all students to communicate effectively and establish Maintain mutual trust between team members and effectively resolve interred-group conflicts; 4. Perform group processing on tasks completed by each individual; 5. Evaluate the effectiveness of joint activities and seek ways to increase their effectiveness. Motivation of cooperation and personal responsibility are the key to successful teaching and learning. If students are in the individual, competitive learning state for a long time, students may become indifferent, selfish, narrow and lonely as time goes by, and cooperative learning helps to cultivate the spirit of student cooperation, team awareness and collective concepts. It also helps to cultivate students' competitive awareness and competitiveness. Cooperative learning can also help students in accordance with their aptitudes and can make up for the insufficiency of a teacher's ability to teach students with differences, thus realizing the goal of making every student develop. Because of the active participation of learners, high-density interaction and positive self-concept in cooperative learning, the teaching process is far more than just a cognitive process, but also a process of communication and aesthetics. Facts have proved that to improve the academic performance of a child, a more effective way is to promote education in his emotional and social consciousness.

\subsection{Explore Independently and Solve Problems}

Inquiry learning refers to the selection and determination of research topics from subject areas or social real life. In teaching, a situation similar to academic (or scientific) research is created. Students independently and independently find problems, experiments, operations, and investigations. Exploration activities such as information collection and processing, expression and communication, access to knowledge and skills, development of emotions and thinking, and in particular exploration of learning methods and learning processes in the development of spiritual and innovative abilities. Contrary to inquiry learning, learning is accepted. Accepted learning presents learning content directly to learners, while learning content in inquiry learning is presented in the form of questions. Compared with receiving learning, inquiry learning is more problematic, practical, participatory and open. Experience the process of inquiry to obtain intellectual and emotional experience, construct knowledge, and master methods for solving problems. This is the three goals that inquiry learning must achieve [5]. "The thought recorded on the paper is like the footprint of someone staying on the sand. We may be able to see the path he has taken. But if you want to know what he saw on the road, you must use our own eyes." The German philosopher Schopenhauer's remarkably demonstrated the value of inquiry learning. Inquiry learning also contributes to the development of students' excellent intellectual qualities, such as: love and cherish learning opportunities, respect facts, and treat critical thinking, understanding, modest acceptance of their own deficiencies, and attention to good things. In his "Analysis of the Beauty," Hogarth proposed that "as a result of people's preconceived prejudices and prejudices, the subject may undergo an astonishing transformation under the artist's pen. Everyone who wants to learn to see the truth must guard against hypocrisy [6]. "To understand the truth, it is necessary to "break" and break the inherent thoughts of the past. Teachers should encourage students to courageously draw what they want to draw, draw what they see, and encourage students to believe in their own eyes.

\subsection{The Lack of Rural Art Teaching Equipment and Equipment}

Roughly speaking, the majority of impoverished areas and 
weak schools are relatively backward in terms of economic conditions, and obviously have no advantage in terms of the curriculum resources that require greater economic input. However, from the point of view of curriculum resources as a source of curriculum elements, even in poor areas and weak schools, the curriculum resources are rich and varied, but the lack of awareness and ability for the identification, development and application of curriculum resources. Therefore, for the poor areas and the weak schools, the problem is that they pay insufficient attention to the status and role of curriculum resources. On the one hand, curriculum resources, especially curriculum resources as a condition for curriculum implementation, are seriously inadequate. On the other hand, due to the weak awareness of curriculum resources, a large amount of curriculum resources, especially curriculum resources as source of curriculum elements are buried, and cannot be processed in time. And after the transformation into the actual primary and secondary school curriculum, resulting in the idle and waste of many valuable curriculum resources. Some elementary and middle schools even regard textbooks as the only curriculum resources, and the concept of curriculum resources is very narrow. In fact, many different materials may differ greatly from the point of view of the curriculum implementation conditions, and if viewed from the perspective of curriculum elements, many different resources are homogeneous in terms of educational value. There is a saying that when American teachers teach students to draw apples, they put a bag of apples and share them one by one, allowing students to see, touch, smell and even bite a few mouthfuls, and then start painting apples. As a result, most students painted watermelons for the first time, like pears the second time, and painted apples like apples for the third or fourth time; while Chinese teachers taught students to draw apples with only one chalk. First, the students of the whole class were asked to draw pictures of Apple's attention, and then they were demonstrated one by one on the blackboard. The students painted pictures according to the teacher's model. As a result, all students first painted like apples. In contrast, although American students are struggling to paint and are not as much like Apple, what they draw is "Apple in Life" and "Own Apple." Although Chinese students draw easily and resemble apples, they draw what came out was the "Apple on the blackboard" and the "Apple of the teacher!" Although this example is a figurative joke, it is not a specific fact, but it can reflect the difference in educational concepts. The significance of the two approaches to student development is very different. Among them, from the perspective of curriculum resources, the resource awareness of the latter approach is relatively weak. Some people may say that Chinese teachers, especially those in poor areas and those in weak schools, have no conditions to send students to apples. However, if we use the perspective of curriculum elements, we do not have the conditions to send apples, but we have land and grass, even if it is barren hills, loess slopes, thatched sheds, their educational value, they are for the realization of curriculum objectives and the development of student experience The meaning and function of expressing beauty is the same. The key lies in how we use them. Of course, this argument must not be the reason why we refuse to improve the implementation conditions of the curriculum, but it should be the driving force for us to develop and use curriculum resources that are sources of curriculum elements. Therefore, as an urgent matter, an important topic is to strengthen the theoretical and practical research on curriculum resources, clarify the concept of curriculum resources, strengthen the awareness of curriculum resources, raise the level of understanding of curriculum resources, and develop and use various curriculum resources according to local conditions. This is especially true for poor areas and weak schools [7].

The new curriculum reform has made natural science classroom teaching a "lifestyle, activity, autonomy, and emotional" path. This is a gratifying phenomenon that makes natural science classroom teaching really close to nature, close to experience, and close to Life, full of vitality.

In the reform of basic art education, the art teacher is the main executor of reform, which brings more thoughts to art education in basic education. In the modern education, the teacher's duties have changed quietly. The teacher has become the promoter of student learning and the organizer of the teaching from the conductor on the stage. When the teacher pushes the student to the front desk to play a leading role, [8] he retreats to himself. Behind the scenes is the role of behind-the-scenes organizations and managers. The teacher's task is to guide students to develop in a personalized way. Today, in the promotion of personalized education, it is an important responsibility of each teacher to improve student's personality. The improvement of student's personality requires that teachers can not only master the professional knowledge of the arts, but also have more professional qualities. This requires that basic art education in higher education not only teaches the basic knowledge of fine arts, but also teaches teachers' duties and knowledge, and it is necessary for students to understand the guiding qualities of art teachers and the significance of being a teacher. [9] The reform of education puts forward higher requirements for today's college students. The art education major is no exception. Our students in the US-major education major must understand the themes of today's education, and must improve their own quality. They must actively adapt to the way of educational reform, keep up with the pace of education reform, and make themselves a qualified professional teacher.

\section{Implementation Method}

\subsection{Carrying Out the Teaching Form of Teaching in Pleasure}

Art appreciation teaching is a curriculum with distinctive characteristics. At present, the new art curriculum in primary and secondary schools has been carefully compiled by the Ministry of Education to organize excellent art education experts, so that the art curriculum in primary and secondary schools covers a wide range and can be implemented. Covers excellent art works, folk art forms of works, sculptures, 
ceramic art, traditional arts and crafts and so on. [10] In local primary and secondary schools, most students have not been exposed to art training. At the same time, due to limited conditions, some primary and secondary school students rarely go to art galleries or museums for on-the-spot viewing, and can not interpret some of the art works in the course. The basic elements of excellent works of Art Materials, composition, creative techniques, colors, painting forms, etc. Folk art forms include paper-cut, shadow, weaving, embroidery, etc. Traditional techniques such as jade carving, stone carving, lacquer art, etc., these courses are involved in art appreciation classes in all grades of primary and secondary schools. [11] Most primary and secondary schools in our country, unlike some primary and secondary schools in big cities, can carry out art lessons in art galleries or museums, and organize teaching intuitively and effectively. The art classroom in rural primary and secondary schools is led by teachers to carry out art appreciation teaching. Whether the classroom effect is good or not depends entirely on the teacher's organization of the classroom. When the teacher analyzes the works of art in the appreciation of art, he faces some Students who have no art foundation talk about their excellence in who has done it, creative techniques and the sense of form of painting, and the results of this kind of teaching can be imagined.

The resources involved in art teaching in primary and secondary schools can be taken in field teaching. Under this advantage, teachers can not stick to books and carry out effective field teaching, [12] such as paper-cut and weaving in folk art appreciation, stone carving in traditional craftsmanship, ceramic making and so on. The materials involved in these courses can be found around you at any time. These ready-made materials can not only provide help for the smooth development of the course, but also enable students to understand the characteristics of engraved materials and really teach students according to their aptitude. In fact, to a certain extent, the purpose of art teaching is not only to convey to students how to do or do what, but in this process, So that students experience the joy of participation, and learn the corresponding knowledge in happiness. Taking stone carving as an example, the teacher gave a lecture on stone carving in class in art teaching. The impression of stone carving in the student's mind is the sculpture made of stone, and there is nothing else. In the field, it is better for every student to feel the texture, hardness, modeling and so on of all kinds of stones. [13] In this process, the students learn visual cognition (look at texture and modeling), learn knowledge about geology (distinguish hardness and stone weathering, etc.), learn what kind of stone to express works (with certain aesthetic judgment), and do the same. Good works can be used as gifts to their parents, teachers and friends, and so on, learn to be grateful, share and give, and so on. Therefore, for primary and secondary schools, flexible and vivid and colorful art classroom is no longer inexplicable, and students' aesthetic enjoyment of art is not out of reach. Students can learn to see, feel and appreciate the pleasure brought by art in art teaching, which will inevitably make art teaching have a significant effect.

\subsection{Appreciate the Artistic Charm in the Appreciation of Excellent Works}

The art appreciation course in art teaching in primary and secondary schools leads students to appreciate excellent works of art, so that they can feel the background, aesthetic characteristics, cultural flavor, narrative content, motivation and emotion of the works by appreciating the works of art. [14] In this process, the students not only appreciate the excellence and greatness of the works, but also receive ideological education. Since it is an art appreciation class, its purpose is one, so that students in the process of accepting art works through appreciation, understanding the process, and produce happy feelings; the second is to identify, is to use their own visual perception, and the existing cultural knowledge to experience art works, theoretical division Analysis and value judgment, from which to obtain relevant knowledge and aesthetic perception.

As an appreciation case, "Qianli Jiangshan Map" plays an important role in the history of painting in China and even in the world. This picture volume in the width of 51.5 centimeters, horizontal length of 1191.5 centimeters to show the landscape of the motherland thousands of miles. [15] In terms of the performance content of the scroll, there are either the deep valley of the rock, or the wild market of the water village, or the activities of the characters such as stream streams, fishing boats, or narrative techniques, which are lifelike in the activities of the characters, such as appreciation, fishing, travel, Hudu and so on. Wang Ximeng, the author of the picture volume, with the expression of "thousands of miles at hand", makes the picture compete for each other, crisscross rivers and rivers, smoke vast, and the momentum is very majestic and magnificent. Mountain Yan Feiquan, tile house thatched, Cangsong repair bamboo, green willow red flowers embellished between them, with great visual impact performance of the motherland Jinxiu River and Mountain. This picture volume is a very good typical art appreciation case, for primary and secondary school students to love the motherland great rivers and mountains patriotism education. In addition, Qianli Jiangshan Picture has more cultural and historical background in artistic expression. When leading the students to appreciate this picture volume, they can understand the historical background of the picture volume from the aspects of landscape scene, composition set, character activity and so on, and appreciate the local customs, geographical style, architectural style, production and life at that time.

Therefore, when appreciating excellent works, art teaching in primary and secondary schools takes an excellent work as a case, not from the surface techniques, composition style to comment, so that there will be a boring teaching atmosphere. What teachers need to do is to understand the historical background, cultural connotation, historical significance and artistic status of the works. 


\section{Conclusion}

The essence of art education is aesthetic education, and aesthetic activities are the process of appreciation and creation based on aesthetic needs and motivation, and knowledge and skills are only the conditions of these aesthetic activities, and only full creation in appreciation and creation is the purpose and destination of aesthetic activities. Creative thinking is different from general thinking activities. It not only needs aggregated thinking, but also needs divergent thinking, and it is more manifested in divergent thinking. Teachers should fully encourage students to be independent, free to divergent thinking, creative imagination, according to their own aesthetic taste, the use of their own mastered tools and materials, to give full play to all skills to express themselves My own aesthetic feeling, shape their favorite image. The germination of creative thinking depends on what students have come into contact with and are familiar with. In practice, students should be guided to learn art extraction, generalize, express their interests and strengthen their artistic appeal according to their subjective feelings. Teachers should dare to praise innovative students, respect their different questions, ideas, and affirm their way of thinking. Our art education should make the educatees develop in an all-round way, so that they can become people with personality, thought, vitality, innovation consciousness and multi-ability. The design of teaching content, the implementation of teaching methods, and the evaluation of teaching results should revolve around the important goal of serving the cultivation of students' creativity.

\section{References}

[1] Li Wei, Yao Benxian. New Theory of Psychology [M]. Beijing: Higher Education Press. 2005, pp. 138.

[2] Ministry of Education of the People's Republic of China. Basic Education Curriculum Reform Outline (Trial) [M]. Shanghai: East China Normal University. 2001: pp. 3-4.
[3] Wu Gangping. Development and Utilization of Curriculum Resources. Contained in "Basic Education Curriculum Outline" (Trial) [M]. Shanghai: East China Normal University. 2001, pp. 403-405.

[4] Thomas. Concise International Education Encyclopedia Curriculum [M]. Beijing: Educational Science Press. 1985, pp 154-155.

[5] Qian Chuan. Art Teaching Theory and Method [M]. Beijing: Higher Education Press. 2005: 119-120.

[6] [UK] William Hogarth, translated by Yang Chengini, Analysis of the Beauty. Guangxi: Guangxi Normal University Press. 2002, pp. 235.

[7] Zhu Muju. Into the new curriculum [M]. Beijing: Capital Normal University. 2004, pp. 216.

[8] Lin Lin. The Teaching Impression of Yiyi Tongtong [J]. Art Grand View. 2013 (07).

[9] Zhao Jie, Ye Hong, Zhang Yan. Reading the Ancient and Modern Taste of Life-Analysis of the Teaching of Appreciation of Art Works [J]. Career Time and Space. 2008 (11).

[10] Zhigang. Let art return to nature [J]. Examination Weekly. 2012 (70).

[11] Yu Feng. Let the source of art flow in the hearts of every student $[\mathrm{J}]$. Middle School Curriculum Counseling (Jiangsu Teacher). 2012 (23).

[12] Zhou Rongjuan. The Interesting Strategy of Art Teaching in Primary Schools [J]. New Courses. 2017 (10).

[13] Zhang Xuemei. On the Importance of Handmade Courses for Art Teaching in Kindergarten [J]. Xueyuan Education. 2014 (11).

[14] Wang Chunzi. On the Application of Flipping Classroom in Art Teaching of Preschool Teachers [J]. Art Education Research. 2017 (23).

[15] Xu Zhe. On the Cultivation of Students' Humanistic Spirit in Art Teaching [J]. Art Education Research. 2017 (24). 